\title{
Jesus, a Torá e os Nebîim, e o pleno cumprimento da justiça em Mt 5,17-20'
}

Marcelo da Silva Carneiro

\section{Introdução}

É possível saber ao certo a relação entre Jesus de Nazaré e a Torá? Que indicativos temos de sua compreensão a respeito da Lei? Conseqüentemente, da vontade de Deus e de sua prática como judeu Galileu, a partir do dito de Mt 5,17-20, considerando-o como dito autêntico? São considerações necessárias para a compreensão do projeto de fé de uma comunidade, segundo o registro do Evangelho de Mateus. A presente comunicação tem como tema a relação de Jesus com a Torá e os Nebîim, e a forma como isso afeta a comunidade de crentes em Cristo.

\section{Jesus e as ordenanças da Lei}

A postura de Jesus diante das ordenanças da Lei está vinculada ao fato dele ter sido criado no ambiente judaico, em que as Escrituras Hebraicas ganham proeminência para as questões da vida. Na verdade, segundo J. Jeremias, "não se pode entender de forma alguma as suas palavras sem o conhecimento do Antigo Testamento."

\footnotetext{
${ }^{1}$ O presente artigo é um estrato da pesquisa de Dissertação de Mestrado de Marcelo da Silva Carneiro, defendida em março de 2008, na PUC-Rj, cujo orientador foi Isidoro Mazzarolo, e foi aprovada sem sugestões ou restrições.

2 JEREMIAS, J., Teologia do Novo Testamento, p.303s.
} 
Há, na postura de Jesus, uma lealdade para com a Lei, e o desejo dele de que seus seguidores também sejam leais a ela. Longe de ser um rebelde contra a religião judaica, Jesus teve nas Escrituras hebraicas o suporte para sua mensagem e ministério. ${ }^{3} \mathrm{G}$. Theissen explica esse processo como uma ambivalência da parte de Jesus na sua relação com a Lei:

\begin{abstract}
Jesus intensificava as normas éticas (sobretudo, o mandamento do amor) em que é nítida uma tendência a um ethos universal. E relativizava as normas rituais (sobretudo os mandamentos sobre a pureza) pelos quais se separa o judaísmo do helenismo - sem eliminar tais normas completamente. $^{4}$
\end{abstract}

Theissen ainda aponta que outros grupos faziam exegese da Lei em linhas semelhantes. No texto de Mt 5,17-20 e os versos seguintes, as antíteses são uma tomada de posição de Jesus frente à Lei. ${ }^{5} \mathrm{O}$ ensino de Jesus sobre a Lei não contradiz aquilo que Moisés ensinou, mas é uma oposição às interpretações correntes desse ensino. J. Gnilka completa, afirmando que "a posição de Jesus em relação à Lei está voltada para a salvação do homem. As concepções da lei que estão em contradição com isto são por ele rejeitadas como não correspondendo à dignidade do homem." ${ }^{16}$

Há na postura de Jesus, no entanto, de forma prática, uma tendência, presente também nos rabinos do primeiro século, de "pesquisar os princípios centrais da Torá, e mesmo sua essência". ${ }^{7}$ Como afirma D. Flusser, "para Jesus havia, naturalmente, o problema peculiar de sua relação com a Lei e seus preceitos, mas o mesmo ocorre com todo judeu crente que leva a sério seu judaísmo". ${ }^{8}$ Com isso, tem-se que pensar em dois fatores: a relação de Jesus com a tradição oral, talvez o principal motivo de questionamento; e a busca dele pelo essencial que, praticado, cumpriria toda a justiça.

\footnotetext{
${ }^{3}$ FILSON, F.V., A Commentary on the Gospel according to St. Matthew, p.83.

${ }^{4}$ MERZ, A. e THEISSEN, G., O Jesus Histórico, p.388.

${ }^{5}$ Ibid., p.389.

${ }^{6}$ GNILKA, J., Jesus de Nazaré, p.207.

${ }^{7}$ VERMES, G., A religião de Jesus, o judeu, p.42.

${ }^{8}$ FLUSSER, D., Jesus, p.37. Entretanto, Maldonado aponta que o dito de Jesus sobre João, em Mt 11,13: "porque todos os Profetas e a Lei profetizaram até João", deve ser entendido como uma declaração do fim da validade da Lei do Antigo Testamento. MALDONADO, J., Comentario a los quatro evangelios, p. 437. Essa interpretação implicaria numa contradição com o dito de Mt 5,17-20.
} 


\section{Jesus não veio anular, mas cumprir}

Jesus não veio anular a Lei e os Profetas, mas cumprir. De que maneira? Os termos $\kappa \alpha \tau \alpha \lambda \hat{v} \sigma \alpha \iota$ e $\pi \lambda \eta \rho \hat{\omega} \sigma \alpha \iota$ devem ser bem analisados para a plena compreensão do dito de Mt 5,17-20.

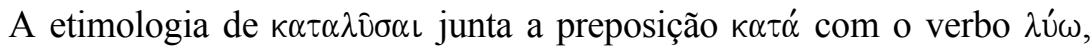
que "é usado em uma variedade de sentidos em conexão com as instituições do judaísmo." "No grego clássico, e de acordo com o uso no Novo Testamento, no ativo tanto pode ter o sentido de "lançar para baixo", "destacar", "destruir", "demolir", "desmanchar", como pode indicar "acabar com", "abolir", "anular", "tornar inválido". ${ }^{10}$ Estes últimos sentidos estão mais próximos do contexto jurídico imediato do v.17, posto que este verbo é considerado um termo chave para discussões em torno da constituição e das leis de um povo na política grega. ${ }^{11} \mathrm{O}$ termo "destruir" é mais apropriado para o sentido de terminar com alguma coisa concreta, como o templo em Mt 24,2. ${ }^{12}$

Em passagens pré-cristãs onde aparece explicitamente o termo Lei, o sentido para $\kappa \alpha \tau \alpha \lambda \hat{v} \omega$ é "abolir" ou "anular" (cf. 2 Mac 2,22; 4 Mac 5,33). ${ }^{13}$ $\mathrm{O}$ verbo não designa uma refutação teórica a respeito da Lei, mas uma atividade própria que liberta ou sustenta os homens para além de sua autoridade. Seria assim, uma polêmica contra o legalismo rabínico. ${ }^{14}$

Qual seria o sentido de "não vim para anular a Lei"? Há algumas possibilidades: a sentença seria uma resposta aos judeus, que o acusavam de destruir a Lei, ou mesmo contrapor essa acusação, contra os escribas e intérpretes da Lei (cf. Mt 7,29; 15,9). Outra explicação seria o dito como uma transição para iniciar a parte do sermão que trata da interpretação mais adequada da Lei, e assim Jesus quis deixar bem claro que não estava destruindo a Lei, mas aperfeiçoando-a, ou seja, explicando-a de acordo com o pensamento do legislador. Assim, há uma interligação com a parte posterior que encabeça as antíteses: "ouvistes o que foi dito aos antigos; (...) eu porém, vos

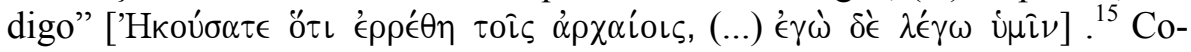

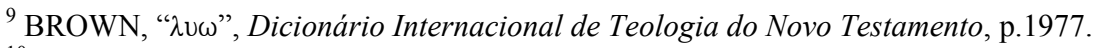

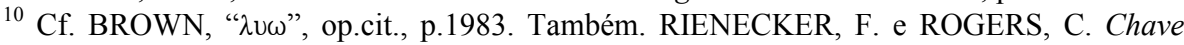
Lingüistica do Novo Testamento, p.254.

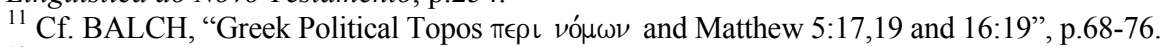

${ }^{12}$ Cf. CARTER, W., O Evangelho de São Mateus, p.190.

13 BANKS, "Matthew's Understanding of the Law", p.229. Martin também aponta esses textos, "Matthew on Christ and the Law" p.65.

${ }^{14}$ BONNARD, L'Evangile selon Saint Matthieu, p.61.

${ }^{15}$ MALDONADO, J., Comentarios a los Cuatro Evangelios, p.247. W.Carter parafraseia da seguinte forma: "o mandamento é conhecido pela audiência (Ouvistes) como palavra de Deus (a forma passiva foi dito) confiada a gerações anteriores (aqueles de tempos antigos)." p.195.
} 
mo aponta I. Mazzarolo, nessa tensão "Jesus revela sua soberania e superioridade absoluta em relação ao que foi dito. Agora não é mais o tempo antigo, arcaico, mas o tempo próprio, novo." 16

Para a comunidade de Mateus isso teve um significado muito importante. A afirmação de Jesus tem, no evangelho, um sentido de advertência para os antinomianos. Segundo Overman, "Mateus acredita que tanto Jesus como sua comunidade, que age de acordo com os ensinamentos de Jesus, são seguidores e cumpridores da Lei." ${ }^{.17}$ Mas de que forma Jesus cumpriu a Lei? É o que veremos a partir do sentido de $\pi \lambda \eta \rho \hat{\omega} \sigma \alpha$, a seguir.

A melhor maneira de entender o sentido de $\pi \lambda \epsilon \rho \hat{\omega} \sigma \alpha \iota$ em 5,17 é buscar o seu correspondente aramaico, de acordo com as pesquisas realizadas a respeito, a partir de textos correlatos do Talmude ${ }^{18}$ Mesmo sendo esse texto posterior ao tempo de Jesus (século III d.C.) ajuda a perceber que palavras podem ter sido usadas com sentido similar, tendo em consideração que ele também se reporta a tradições rabínicas mais antigas. Conforme o estudo de Jeremias, o Tb Shabbat $116 \mathrm{~b}$ afirma:

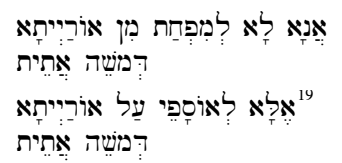

Eu não vim para tirar algo

da lei de Moisés

Antes, vim para acrescentar

à lei de Moisés

No caso desse texto $\kappa \alpha \tau \alpha \lambda$ ú $\sigma \alpha \iota$ (anular) corresponde ao aramaico (tirar fora), e $\pi \lambda \epsilon \rho \omega \sigma \sigma \alpha \iota$ (cumprir) corresponde ao aramaico אוֹסָפי (aumentar, acrescentar, alargar). Assim, Jeremias afirma que a tradução de 'osape ("acrescentar") com $\pi \lambda \epsilon \rho \hat{\omega} \sigma \alpha \iota$ [tornar pleno] no grego expressa adequadamente que o propósito do "preenchimento" é atingir a medida plena. Temos aí a

\footnotetext{
${ }^{16}$ MAZZAROLO, I., Evangelho de Mateus, p.88.

${ }^{17}$ OVERMAN, A., O Evangelho de Mateus e o Judaísmo Formativo, p.93.

${ }^{18}$ Especialmente o Shabbat 116a, cf. BILLERBECK, Kommentar zum Neuen Testament aus Talmud und Midrasch I, p.241; JEREMIAS, J., (cita como Shabbat 116b), Teologia do Novo Testamento, p.142 et.seq.; BARTH, "Matthew's Understanding of the Law", p.92 et.seq.; MARTIN (também cita o Shabbat 116b), "Matthew on Christ and the Law", p.65 et.seq.

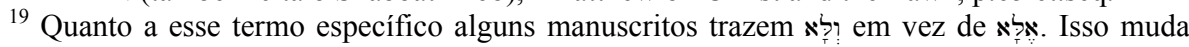
totalmente o sentido, pois o primeiro significa "nem", ou seja, Jesus não teria vindo nem para tirar, nem para acrescentar nada à Lei. O segundo, conforme constatada na tradução, aponta para a mudança que Jesus veio trazer. Jeremias preferiu o segundo sentido, conforme consta no texto apoiado também num texto do cristianismo judaico, o Recognitiones Pseudoclementinas, e numa fonte judaico-cristã, que afirma pelo sentido de Jesus não veio "para diminuir, mas, pelo contrário, para completar". Cf. JEREMIAS, op.cit., p.144.
} 
idéia da medida escatológica, que Jesus usa em outros lugares; $\pi \lambda \in \rho \omega \hat{\sigma} \sigma \iota$ é, portanto, um termo técnico escatológico. ${ }^{20}$

J. Jeremias, nesse sentido, considera que Mt 5,17 é a "expressão mais aguda" da consciência de plenipotência de Jesus. Para ele o ponto central do

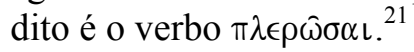

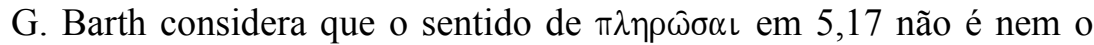
simples "fazer", como cumprimento mecânico da Lei, nem "determinar" o verdadeiro sentido dos mandamentos, mas "estabelecer" a Lei e os Profetas, como o próprio estabelecimento da vontade de Deus. Isso é marcado pelo fato da obra de Cristo ser precisamente a realização da vontade de Deus, de acordo com a cristologia de Mateus. Esse sentido se aproxima, da mesma maneira, do sentido de $\pi \lambda \eta \rho \omega \sigma \sigma \alpha$ em 3,15. De fato, o estabelecimento do juízo de Deus é o pano de fundo desse dito, bem como o de 3,15. Especialmente os versos 17 e $18 \mathrm{c}$ pertencem a esse contexto, que indica o fato de que o ensino de Jesus em $\pi \lambda \eta \rho \hat{\sigma} \sigma \alpha \iota$ está vinculado com o estabelecimento da Lei, da vontade de Deus. ${ }^{22}$

Sob o aspecto teórico o "cumprimento da lei" é apresentado essencialmente em três sentidos: como retorno à vontade de Deus $(19,1-9 ; 15,4)$, como concentração no mandamento do amor $(23,39 \mathrm{~s})$ e como realização prática por meio da acentuação perfeita. $\mathrm{O}$ amplo conceito de "cumprimento" comporta esta aplicação múltipla. O elemento decisivo do "cumprimento" se acha na concentração no mandamento do amor. ${ }^{23}$ De fato, o "cumprimento não deve ser entendido de modo formal." ${ }^{24} \mathrm{O}$ fundamento para o cumprir de Jesus é o amor, o qual Jesus demonstrou desde o início, quando declarou que estava cumprindo toda a justiça $(3,15)$.

O cumprimento se dá não a partir da prática das normas de forma rigorosa, mas de sua essência, através da qual o cumprimento de certo preceito abrange os demais. Ademais, há o fato de que Jesus não foi o único a desejar resumir a Lei numa busca por seu sentido ético mais amplo. É preciso simplificar o sentido do texto, pois, "seguindo a linguagem costumeira de sua época, ele evitou a acusação de que a exegese da Lei que se seguia ab-rogava o significado original das palavras da Bíblia". ${ }^{25}$

\footnotetext{
${ }^{20}$ Ibid., p.144.

${ }^{21}$ Ibid., p. 142 .

${ }^{22}$ BARTH, G., "Matthew's understanding of the Law", p.69 et passim

${ }^{23}$ DAUTZENBERG e SCHREINER, Formas e exigencias do Novo Testamento, p.292.

${ }^{24}$ SCHIPPERS, “cumprir”, Dicionário Internacional de Teologia do Novo Testamento, p.1676.

${ }^{25}$ FLUSSER, D., Jesus, p.65.
} 


\section{Como Jesus cumpriu a Lei}

Jesus foi circuncidado ao oitavo dia (cf. Lc 2,21), o que em si já indica que o seu ambiente natural foi como judeu observante da Lei. Dentro da tradição transmitida pelos evangelistas - mesmo com as interferências redacionais em relação aos eventos - transparece em vários momentos esse respeito à Lei, ao mesmo tempo de uma aparente liberdade na interpretação de questões pontuais.

Sem dúvida, são delas que Jesus mais se ocupa, e às quais dá interpretações mais fortes. Tanto as antíteses $(5,21-48)$ quanto outras orientações ou respostas de Jesus no tocante a aspectos da lei moral (a questão familiar em Mt 12,50; 10,37; 8,21-22; bem como o divórcio em 19,3-12) parecem direta ou indiretamente relacionar-se com o decálogo - os pronunciamentos associados a Moisés no monte Sinai. ${ }^{26}$ As antíteses tem, em sua maioria, essa ligação conforme quadro abaixo: ${ }^{27}$

\begin{tabular}{|l|l|l|l|}
\hline Antítese & Texto & Tema & Relação na Torá \\
\hline Primeira & $5,21-26$ & Homicídio & Ex 20,13 \\
\hline Segunda & $5,27-30$ & Adultério & Ex 20,14 \\
\hline Terceira & $5,31-32(19,3-12)$ & Divórcio & Dt 24,1.3 \\
\hline Quarta & $5,33-37$ & Juramento & Ex 20,7 / Lv 19,12 \\
\hline Quinta & $5,38-42$ & Vingança & Ex 21,24 / Lv 24,20 \\
\hline Sexta & $5,43-48$ & O amor ao próximo & Lv 19,18.34 \\
\hline
\end{tabular}

Pelo quadro acima, percebe-se que, em três antíteses $\left(1^{\mathrm{a}}, 2^{\mathrm{a}}\right.$ e $\left.4^{\mathrm{a}}\right)$ Jesus analisou leis diretamente do Decálogo. As demais são citadas de partes diversas da Lei de Moisés, mas foram colocadas numa ordem que demonstra que o objetivo de Jesus na observância da Lei é, acima de tudo, o amor ao próximo, o qual deve reger o relacionamento entre as pessoas. ${ }^{28}$

Quanto às polêmicas sobre a lealdade familiar, está sempre em questão o mandamento do decálogo sobre os pais, em Ex 20,12. Não há uma discussão formal sobre o assunto, mas encontramos algumas situações que podem transparecer um certo descaso para com a família. Quando um discípulo desejou seguir Jesus, mas pediu para aguardar a morte dos pais, ele respondeu: "Segue-me, e deixa aos mortos o sepultar os seus próprios mortos" (8,21-22). Em seu discurso de envio aos discípulos (cap. 10), ele adverte que o amor aos pais não pode sobrepor-se ao amor por ele: "Quem ama o pai

\footnotetext{
${ }^{26}$ Cf. VAUX, R.de., Instituições de Israel no Antigo Testamento, p.176.

${ }^{27}$ Seguimos a divisão das antíteses de VOUGA, Jesus et la Loi, p.200-274.

${ }^{28}$ ZUMSTEIN, J. Mateus o Teólogo, p.49 et.seq.
} 
ou a mãe mais do que a mim não é digno de mim; e quem ama o filho ou a filha mais do que a mim não é digno de mim" (10,37). Em outra ocasião, quando ensinava aos seus discípulos e foi dito a ele que sua família o aguardava do lado de for da casa, ele disse: "Porque, qualquer que fizer a vontade de meu Pai que está nos céus, este é meu irmão, e irmã e mãe" $(12,50)$. Como entender essa aparente distância e até mesmo certa negligência para com a família?

Uma possibilidade pode ser a idéia apontada por Crossan, de que as famílias ficariam divididas por causa de Jesus, e ele sabia disso, porque ele "romperá a família hierárquica ou patriarcal pelo meio, ao longo do eixo de dominação e subordinação." 29 Ou seja, a exemplo do que Jesus apontou na questão do divórcio, não haverá mais relações de dominação entre pessoas, mesmo que na família. ${ }^{30}$

$\mathrm{Na}$ verdade Jesus intensificou a lei do amor, ao ponto de renunciar a toda violência, mesmo permitida pela Lei, e apontando para necessidade de amar o inimigo, pois isso seria um sinal de uma justiça superior. Como afirma Stegemann: "precisamente no assim chamado mandamento do amor ao inimigo desdobram-se princípios contidos na Torá e que, de alguma forma, é possível falar de uma superação da mesma." ${ }^{\text {31 }}$ Essa foi uma idéia que as comunidades seguidoras de Jesus acolheram dele mesmo, não sendo jamais uma elaboração posterior.

Tendo em vista uma interpretação apropriada da Lei, Jesus a resumiu em situações de debate e ensino. Os sumários representam a busca de uma síntese que facilite e englobe toda a Lei, considerada como vontade de Deus, num único grande mandamento. Isso também ocorria no Judaísmo, de acordo com famosa história relacionada a dois grandes mestres: um gentio foi procurar Shammai e pediu: "Faz de mim um prosélito, sob a condição de me ensinares toda a Torah enquanto me mantenho sobre uma perna só." Sham-

\footnotetext{
${ }^{29}$ CROSSAN, O Jesus Histórico, p.337.

${ }^{30}$ Entretanto, uma das severas críticas de Jesus aos fariseus foi exatamente sobre o descuido deles com os pais idosos, na controvérsia sobre descumprir mandamentos (Mt 15,3ss). Em sua argumentação contra os fariseus, Jesus analisa o fato dos fariseus se preocuparem deveras com esse tipo de ordenança legal, esquecendo-se, no entanto, de guardar preceitos morais fundamentais. No caso, exatamente de "honrar pai e mãe" (Ex 20,12) e a advertência de que "aquele que amaldiçoar pai ou mãe seja punido de morte" (Dt5,16). O que os fariseus faziam estava fundamentado no korban, uma oferta separada a Deus que não podia ser utilizada de modo comum. O problema é que eles separavam aquilo que seria destinado aos seus pais idosos; com isso, tornavam-se isentos de cumprir o mandamento. Mas Jesus desmascarou essa farsa e condenou-os por violar o mandamento moral. ${ }^{30} \mathrm{~A}$ conclusão a que se chega é que Jesus só colocava a família numa condição menor, quando se tratava de cumprir a missão confiada a ele, de proclamar o reino de Deus.

${ }^{31}$ STEGEMANN, E., W.,História social do protocristianismo, p.242.
} 
mai o expulsou com um bastão, e ele foi até Hillel, que o tornou prosélito, e o ensinou: "O que é odioso para ti, não faças a teu próximo; isto é toda a Torah e o resto não passa de comentário; vai e estuda.",32

Jesus fez resumo similar daquele de Hillel, quando declarou: "Portanto, tudo o que vós quereis que os homens vos façam, fazei-o também vós, porque esta é a Lei e os Profetas." (Mt 7,12), que também faz parte do Sermão do Monte. Outra expressão que tem o mesmo objetivo está em Mt 22,34-40. Argüido sobre qual seria o grande mandamento da Lei por um

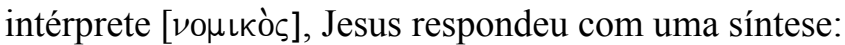

E Jesus disse-lhe: Amarás o Senhor teu Deus de todo o teu coração, e de toda a tua alma, e de todo o teu pensamento. Este é o primeiro e grande mandamento. E o segundo, semelhante a este, é: Amarás o teu próximo como a ti mesmo. Destes dois mandamentos dependem toda a Lei e os Profetas. (22,37-40)

Nos dois casos fica claro que se trata de uma síntese, tendo em vista a conclusão, que cita a Lei e os Profetas. E qual é o sentido máximo da vontade de Deus, expressa na Lei e nos Profetas, para Jesus? O amor e a misericórdia, que de certa forma são indicados na perícope de 5,17-20,.$^{33}$

Assim, transparece na interpretação e atitudes de Jesus o desejo pela total observância da Lei, a partir de uma busca pelos mandamentos que irão definir toda a postura ética. Theissen aponta que essa ética está entre a Sabedoria e a Escatologia. De um lado Jesus tem motivos sapienciais, pois em diversos momentos utiliza elementos sapiências, "quando se refere à criação como passado primevo ou como natureza presente". ${ }^{34}$ De outro, vemos em Jesus motivos escatológicos em sua ética, por causa do conceito - já trabalhado acima - de "recompensa e castigo no novo mundo ou do Reino vindouro de Deus. A escatologia propicia a motivação." 35

\section{A justiça como plenitude da Lei}

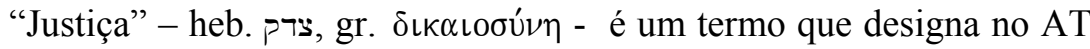
uma relação conectiva: entre o jurídico e o salvífico; entre Deus e os homens. Aponta para uma conduta relacionada com a comunidade, de fidelida-

\footnotetext{
${ }^{32}$ T.B. Shabbat 30b-31a. Citado apud COLLIN, M. e LENHARDT, J., A Torah Oral dos fariseus, p.23. Também VERMES, G. A Religião de Jesus, o judeu, p.44.

${ }^{33}$ VERMES, G., A religião de Jesus, o judeu, p.35 passim;186.

${ }^{34}$ MERZ, A. e THEISSEN, G., O Jesus Histórico, p.401.

${ }^{35}$ Ibid., p.403.
} 
de a ela, regulamenta o relacionamento entre as pessoas, por isso tem estreita relação com a "misericórdia" [7๐ח]. ${ }^{36}$

No NT há diversos conceitos para "justiça", todos vinculados ao sentido semita de relação, ação concreta, e não ao sentido grego de um ideal de virtude. ${ }^{37}$ Paulo foi quem mais tratou do assunto, numa perspectiva um pouco diferente daquela de Mateus. ${ }^{38}$ Mas depois de Paulo, Mateus é quem mais

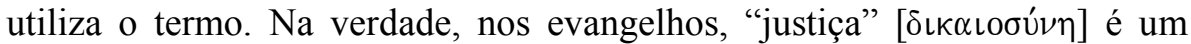
termo tipicamente mateano - aparece sete vezes em Mt (Mt 3,15; 5,6.10.20; $6,1.33 ; 21,32)$ e apenas uma vez nos outros sinópticos (Lc 1,75). ${ }^{39}$ É um tema central no Sermão do Monte, pois aparece ali cinco vezes. ${ }^{40}$

Quanto ao sentido de "justiça” para a compreensão de 5,17-20, há várias maneiras de interpretá-10 ${ }^{41}$. Analisando o termo, porém, entende que a melhor maneira de compreender a "justiça" - ele denomina "justiça/retidão" - leva em conta que Deus age como justo ao agir em conformidade com a Aliança na qual se comprometeu de salvar o povo (cf. 51,$14 ; 65,5$; Is 46,13 ; 51,5-8). Em contrapartida, o povo de Deus é justo na medida em que se mantém fiel às exigências da aliança. Ou seja, para haver justiça plena, é preciso haver o agir de Deus de forma salvífica, ao mesmo tempo em que os homens cumprem suas exigências. ${ }^{42}$ Isso se dá, de forma especial, no relato do batismo de Jesus, e esse seria o sentido de "cumprir toda a justiça" de 3,15 . $^{43}$ Com esse ato, Jesus se tornou o "modelo e fundamento possibilitador" 44 de uma justiça superior. O texto de 21,32 tem relação com 3,15. Nele, Jesus afirma que "João veio a vós no caminho da justiça", numa disputa a respeito

\footnotetext{
${ }^{36}$ OTTO, "Justiça (AT)", Dic Bib Teo, p.222 et.seq.

${ }^{37}$ KERTELGE, "Justiça (NT)", Dic Bib Teo, p.224.

${ }^{38}$ Essa diferença foi analisada, por ex, por ZUMSTEIN. Ele levanta a questão, que muitos também relacionam, de que conceito de justiça em Mateus e Paulo é diferente. Enquanto para este, a justiça se apresenta na forma como Deus justifica o pecador, que a recebe pela fé, Mateus indica que o crente, ao cumprir a Lei, pode aspirar à justiça, cujo caminho foi apontado por Jesus no Sermão do Monte. Mateus o Teólogo, p.43. Ver Também a discussão levantada por BARTH, "Matthew's understanding of the Law", p.159 et.seq.

${ }^{39}$ Cf, BARTH, G., "Matthew's understanding of the Law", p.138 et.seq.

${ }^{40}$ MARTIN, B.L., "Matthew on Christ and the Law", p.60.

${ }^{41}$ Cf. CARTER, W., op.cit., p.143.

${ }^{42}$ Cf. BULTMANN. R., Teologia do Novo Testamento, p.49.

${ }^{43}$ CARTER. W., O Evangelho de São Mateus, p.143; MARGUERAT, D. Le jugement dans l'Évangile de Matthieu, p.136 et.seq.; BORNKAMM, G., "End-Expectation and Church in Matthew", p.36 et.seq. Nesse texto ele afirma a necessidade do Messias cumprir a plena vontade de Deus na terra, desde que foi proclamado como "Filho de Deus"; G. BARTH acrescenta a idéia de "dom escatológico" para a justiça cumprida por Jesus, e como apontado acima, se deu pela sua humilhação de se colocar no mesmo nível dos pecadores. "Matthew's understanding of the Law", p.140.

${ }^{44}$ ROLOFF, J., A Igreja no Novo Testamento, p.175.
} 
de sua autoridade com os "príncipes dos sacerdotes e os anciãos do povo" (cf. v.23). Aqui "justiça" representa a obediência de João ao mandato de Deus e sua pregação pelo arrependimento, e a qual meretrizes e publicanos aderiram. ${ }^{45}$

De um modo geral, Mt usa o termo "justo" para quem vive e age de acordo com a vontade de Deus, e o agrada. Isso está relacionado aos justos e profetas do AT (em 13,17 e 23,29.35), como para pessoas contemporâneas a Jesus (como José, em1,19), e ainda para os fiéis escatológicos, que seguiram a Jesus e se apresentarão a ele no fim $(25,37.46) .{ }^{46}$ Por outro lado, pode-se pensar que a ética exigida a partir da justiça é inteiramente encarada a partir da perspectiva do juízo. Quando a justiça humana está vinculada à vontade divina, sanciona o juízo de Deus. ${ }^{47}$

Nesse último sentido esta a importância do substantivo "justiça", pois para entrar no reino dos Céus, é preciso ter a "justiça superior" "48, que supera a dos escribas e fariseus. É onde o Sermão do Monte demonstra ter um centro temático: a prática de uma justiça que exceda qualquer outra, que não seja baseada no ensino de Jesus. ${ }^{49}$ Como G. Bornkamm comenta:

Isto se torna claro justamente nas antíteses do Sermão da Montanha. Nelas, a exigência de Deus se torna extremamente simples. (...) “.... as antíteses mostram que Jesus já considerou a mentalidade como ação; ela têm por objetivo a obediência até à ação concreta: 'Quem ouvir estas minhas palavras e as puser em prática...!". 50

Assim, o v.20 aprofunda o apelo à obediência total. Mas de forma polêmica, pois a justiça exigida é a total obediência à Lei, conf. demonstrado nos v.17-19. A originalidade de Mt está no "comportamento de acordo com a vontade de Deus que abre as portas da salvação. A ética torna-se a única via que conduz à aprovação divina.. ${ }^{, 51}$ Ou seja, espera-se um agir adequado.

E qual é o agir esperado? É um agir a partir da exigência de uma justiça absolutamente nova, que exceda em muito a justiça dos escribas e fari-

\footnotetext{
${ }^{45}$ Cf. MARGUERAT, D. Le jugement, p.292 passim.

${ }^{46}$ KERTELGE, "Justiça (NT)", Dic Bib Teo, p.225.

47 MARGUERAT, D., Le jugement, p.138. Ele complementa: "La justice n'est pas envisageane en dehors de la Torah, une justice 'meilleure' que celle des scribes et pharisiens encore moins qu'une autre." P.138 et.seq.

${ }^{48}$ Cf. MAZZAROLO, I., Evangelho de São Mateus, p.87.

${ }^{49}$ Cf. BORNKAMM, G.,Jesus de Nazaré, p. 175 et.seq.

${ }^{50}$ Ibid., p.178 et.seq.

${ }^{51}$ ZUMSTEIN, J., Mateus o Teólogo, p.42.
} 
seus, e por isso seja mais perfeita. ${ }^{52} \mathrm{O}$ dito apresenta o verbo $\pi \epsilon \rho \iota \sigma \sigma \epsilon u ́ \omega$, que significa "abundar", "ser a mais", "sobrar". ${ }^{33}$ É um verbo muito utilizado na linguagem paulina ${ }^{54}$ mas que Mt também usa algumas vezes: duas vezes com sentido de advertência para os discípulos (Mt 13,12; Mt 25,29) e uma vez como crítica aos fariseus $(12,34)$. Também aparece nas duas narrativas da multiplicação dos pães, em 14,20 e 15,37, ao descrever a abundância de alimentos, mesmo após a partilha.

O dito de 13,12 fala sobre dar e tirar, inserido dentro da explicação sobre a parábola do semeador: "Porque àquele que tem, se dará, e terá em abundância; mas àquele que não tem, até aquilo que tem lhe será tirado." Vem de Marcos, e aponta para o perigo da pessoa conhecer os mistérios do reino e não corresponder a eles. Da mesma forma, em 25,29, em outra parábola (dos talentos) Jesus adverte sobre "enterrar" o dom entregue a cada um: "Porque a todo aquele que tiver será dado, e terá em abundância; mas ao que não tiver até o que tem ser-lhe-á tirado."; pode se referir àqueles que ouviram o Evangelho e não o tomaram com convicção, antes se fecharam à sua proposta. ${ }^{55}$ Nos dois ditos, o resultado de quem acolheu e viveu é a abundância $[\pi \epsilon \rho\llcorner\sigma \sigma \epsilon \cup \theta \dot{\eta} \sigma \epsilon \tau \alpha \iota]$. Quem não o fez, perderá até o que não tem (seria uma falsa justiça?).

Já o dito de 12,34 é uma severa crítica dirigida aos fariseus: "Raça de víboras, como podeis vós dizer boas coisas, sendo maus? Pois do que há em abundância no coração, disso fala a boca." Está inserido numa perícope de $\mathrm{Q}^{56}$, mas é material exclusivo de Mateus, pois essa afirmação não consta da paralela. Ao mesmo tempo, o texto da Bíblia de Nestlé-Aland aponta que é paralela de Mt 7,15-20, uma palavra dirigida aos discípulos, advertindo-os dos "falsos profetas" [ $\psi \epsilon \cup \delta$ oт $\rho \circ \phi \eta \tau \omega \nu]$, que não dão bons frutos. ${ }^{57} \mathrm{O}$ verso seguinte dessa perícope é muito revelador: "Nem todo o que me diz: Senhor, Senhor! entrará no reino dos céus, mas aquele que faz a vontade de meu Pai, que está nos céus." $(7,21)$, pois aponta claramente o critério para entrar no reino dos Céus: seguir ao Senhor e praticar seus mandamentos. E aqui retornamos ao princípio de 5,20.

${ }^{52}$ LAGRANGE, M. Évangile selon Saint Matthieu, p.96.

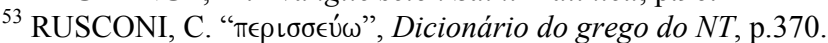

${ }^{54}$ Cerca de 25 vezes, em várias formas verbais, como em Fp 1,9.26; 1 Co 14,12; 2 Co 8,7s; 9,$8 ; 15,58 ; \mathrm{Cl} 2,7 ;$ etc.

${ }^{55}$ Cf. MAZZAROLO, Evangelho de Mateus, p.203; CARTER, O Evangelho de São Mateus, p.365.

${ }^{56}$ Paralelo em Lc 6,43-45.

${ }^{57}$ NESTLÉ-ALAND, Synopsis of the Four Gospels, p. 62. 
Em 5,20, o adjetivo $\pi \lambda \epsilon \hat{\imath}{ }^{\circ} \nu$ - "cheio", "numeroso" - se junta a $\pi \epsilon \rho \iota \delta$ $\sigma \in \dot{\sigma} \sigma \eta$, dando a este uma intensidade afirmativa, por isso se traduz "exceder em muito" ${ }^{58}$ É essa expressão que vai determinar a medida da justiça que os discípulos terão que praticar: superior a dos grupos contemporâneos que se arrogam como intérpretes da Lei. ${ }^{59}$ Jesus valorizou as exigências do Decálogo, mas propõe uma vivência nova, com uma ótica renovada; as antíteses demonstram como ele tratou da essência da Lei que deveria ser praticada. ${ }^{60}$ Sem isso há um enfático "de modo nenhum" [oủ $\mu \grave{\eta}$ ] que aponta para a impossibilidade de se entrar no reino dos Céus. ${ }^{61}$

Não é um mero acumular de atos isolados de justiça que darão esse resultado, que é o motivo de fracasso dos fariseus, segundo Mt. "Trata-se de uma total dedicação a Deus e ao próximo, dedicação essa que determina inteiramente o relacionamento entre ambos.. ${ }^{\circ 2}$ Essa exigência, vinda do próprio Jesus, foi acolhida por Mateus de maneira irresoluta, e certamente dirigida vida de sua comunidade.

Considerando o que apontamos aqui, não é de se admirar que o ensino sobre a justiça superior tenha, em sua essência, uma idéia escatológica. Ou seja, a recompensa pela fidelidade aos ensinos de Jesus não se dará nesse mundo, mas no reino dos Céus. O final do Sermão do Monte ilustra a exigência de Jesus em forma de advertência para a comunidade. Na perícope de 7,21-23, consta o seguinte: "Nem todo o que me diz: Senhor, Senhor! entrará no reino dos céus, mas aquele que faz a vontade de meu Pai, que está nos céus." (v.21) Há uma relação direta entre o agir segundo a vontade de Deus e o entrar no reino dos Céus. Segundo a perícope, o que determina a entrada é a prática do amor, que não é citado textualmente, mas está subjacente ao tema, tendo em vista, que elementos como a prática do exorcismo, da profe-

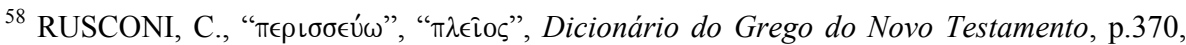
376; RIENECKER, Chave Lingüistica do NT Grego, p.10

${ }^{59}$ TRILLING, W., EL verdadeiro Israel, p.264.

${ }^{60}$ PARISI, S. "Mt 5,17-20: giustizia superiore e fede 'estroversa'.” P.54. F. V. FILSON acrescenta: "The gospel brings mercy, comfort, and divine help, but it does not cancel the demand of God for faithful and complete obedience to his will. A commentarya on the Gospel according to St. Matthew, p.84.

${ }^{61}$ Cf. JEREMIAS, J., Estudos no Novo Testamento, p.100; Também STANTON, A Gospel for a new People, p.322.;

${ }^{62}$ GOPPELT, Teologia do Novo Testamento, p.457. Paralelamente, Lucas trabalha esse tema na Parábola do "Bom" Samaritano (Lc 10,30-37), a qual aponta para o verdadeiro cumprimento do amor ao próximo: servir a qualquer pessoa necessitada de uma ajuda concreta. Não importa quem o faça, será esse que demonstrará amor ao próximo. Em Mateus o samaritano estaria cumprindo a justiça superior.
} 
cia e da realização de milagres não qualificam ninguém como tendo feito a vontade de Deus.63

Marcelo da Silva Carneiro

Mestre em Teologia pela PUC-RJ

Coordenador do Curso de Teologia do Centro Universitário Metodista Bennett - Rio de Janeiro - RJ prmscarneiro@yahoo.com.br

\section{Referências Bibliográficas}

BANKS, R. "Matthew's Understanding of the Law: Authenticity and Interpretation in Matthew 5:17-20", in: Journal of Biblical Literature, n.93, v.2, [S.I.:s.n.], 1974.

BARBAGLiO, G., FABRIS, R., MAGGIONI, B. Os Evangelhos, vol. I. São Paulo: Edições Loyola, 1990.

BARTH, G., BORNKAMM, G. Tradition and Interpretation in Matthew. Philadelphia: The Westminster Press, pp.58-164, 1963.

BILLERBECK, P., STRACK, H. L. Kommentar zum Neuen Testament aus Talmud und Midrasch. Munchen: Beck. 1965. 6 v. em 7.

BORNKAMM, G. Bíblia - Novo Testamento. Introdução aos seus escritos noquadro da história do cristianismo primitivo. $3^{\mathrm{a}}$ ed. São Paulo: Teológica, 2003.

Jesus de Nazaré. 15a ed. Alemã. São Paulo: Teológica, 2005.

BROWN, R. E, FITZMEYER, J. A. Comentario Bíblico "San Jeronimo". Tomo III, Nuevo Testamento, I. Madrid: Ediciones Cristandad, 1972.

BUltMANN, R. Teologia do Novo Testamento. São Paulo: Teológica, 2004. CARTER, W. O Evangelho de São Mateus: comentário sociopolítico e religioso a partir das margens. São Paulo: Paulus, 2002.

FILSON, F.V. A commentary on the Gospel according to St. Matthew. London: Adam e Charles Black, 1977.

FLUSSER, D. Jesus. São Paulo: Editora Perspectiva, 2002.

O Judaísmo e as origens do Cristianismo, vol I e III. Rio de Janeiro:

Imago Editora, 2002.

GARCIA, P.R. O Sábado do Senhor teu Deus. O Evangelho de Mateus no Espectro dos Movimento Judaicos do I Século. Tese doutoral. São Paulo, UMESP, 2001.

${ }^{63}$ MAZZAROLO, I., Evangelho de Mateus, p.123. 
GNILKA, J. Jesus de Nazaré. Mensagem e História. Petrópolis: Vozes, 2000.

GOPPELT, L. Teologia do Novo Testamento. $3^{\mathrm{a}}$ ed. São Paulo: Teológica; Paulus, 2003.

JEREMIAS, J. As parábolas de Jesus. $9^{a}$ ed. São Paulo: Paulus, 2004. . Estudos no Novo Testamento. São Paulo: Editora Academia Cristã, 2006. . Jerusalém no tempo de Jesus. Pesquisas de história econômico-social

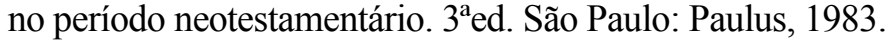

. Palavras desconhecidas de Jesus. São Paulo: Editora Academia Cristã, 2006.

. Teologia do Novo Testamento. $2^{a}$ ed. São Paulo: Teológica, Paulus, 2004.

LAGRANGE, Marie. Évangile selon Saint Matthieu. $7^{\mathrm{a}}$. ed. Paris: Librairie Lecoffre. 1948.

MALDONADO, J. Comentarios a los Cuatro Evangelios. Biblioteca de Autores Cristianos. Madrid: Editorial Catolica, 1956.

MARGUERAT, D. Le jugement dans l'Évangile de Matthieu. Genève: Éditions Labor et Fides, 1995.

MAZZAROLO, I. Evangelho de São Mateus. Ouvistes o que foi dito aos antigos...? Eu, porém, vos digo...! Coisas velhas e coisas novas! Rio de Janeiro: Mazzarolo editor, 2005.

MERZ, A., THEISSEN, G. O Jesus Histórico. Um manual. $2^{\text {a }}$ ed. São Paulo: Edições Loyola, 2002.

OVERMAN, J. A. O Evangelho de Mateus e o Judaísmo Formativo. O mundo social da comunidade de Mateus. São Paulo: Edições Loyola, 1997.

PARISI, S. "Mt 5,17-48: Giustizia superiore e fede 'estroversa'. La morale sociale da 'un punto de vista' della Scrittura.", in: Vivarium (Catanzaro) vol. 2, n.1, [S.I.:s.n.], 1994.

ROLOFF, J. Trad. de N. Schneider. A Igreja no Novo Testamento. São Leopoldo: Sinodal, Centro de Estudos Bíblicos, 2005.

STEGEMANN, E., W. História Social do protocristianismo. Os primórdios no judaísmo e as comunidades de Cristo no mundo mediterrâneo. São Paulo: Paulus, São Leopoldo: Sinodal, 2004.

VERMES, G. A religião de Jesus, o Judeu. Rio de Janeiro: Imago Editora, 1995.

. Jesus e o mundo do Judaísmo. São Paulo: Edições Loyola, 1996. O Autêntico Evangelho de Jesus. Rio de Janeiro: Record, 2006.

Leitura do Evangelho segundo Mateus. $2^{a}$ ed. São Paulo: Edições Paulinas, 1985. 